\title{
Evaluation of antioxidant and gastroprotective activities of ethyl acetate extract of Avicennia schaueriana.
}

\author{
Borba A.D.L1; Barbosa J.A.P2; Santana M.A.N3; Coutinho L.L4; Farias L.O5; Silva T.G6
}

1Student of the Pharmacy Course - UFPE; 2,3,6Researchers of Department of Antibiotics- UFPE; 4,5Students of the Biomedicine Science Course- UFPE

\section{ABSTRACT}

Introduction: Brazilian flora has a great biodiversity and some of these plants are used in folk medicine. Avicennia schaueriana, popularly known as black mangrove, is an endemic specie of mangrove vegetation belonging to the Acanthaceae family. The species of the genus Avicennia are widely used by traditional communities for the treatment of tumors, rheumatism, ulcers and wound healing. Objectives: To evaluate the antioxidant and gastroprotective properties of the ethyl acetate extract of Avicennia schaueriana. Methodology: The ethyl acetate extract of the leaves of A. schaueriana (As-AcEOt) was obtained by maceration, and afterwards the phytochemical prospecting was evaluated by thin layer chromatography (TCL). The antioxidant potential of the As-AcEOt was evaluated by free radical scavenging method ABTS+ (2,2-azobis - (3-ethylbenzthiazoline-6-sulfonate). The gastroprotective activity of As-AcEOt (50, 100 and $200 \mathrm{mg} /$ $\mathrm{kg}$ ) was analyzed by the ethanol-induced ulcer method in Wistar rats. The myeloperoxidase (MPO) levels and histopathological analysis were evaluated in gastric mucosa of the animals treated with As-AcEOt submitted to the model of ulcer induced by ethanol. Results and Discussion: Through TCL was observed the presence of terpenoids, flavonoids and tannins in the extract. The As-AcEOt exhibited antioxidant activity with $73.23 \%$ inhibition of the radical ABTS+. In the gastroprotective activity, the AsAcEOt reduced the ulcerative lesion index (ULI), with percentages of ULI of $83.8,88.5$ and $86.9 \%$ for the doses of 50,100 and $200 \mathrm{mg} / \mathrm{kg}$, respectively. The histological analysis showed that As-AcEOt preserved the gastric pits and it did not present hemorrhage and edema. Conclusion: This research showed that AsAcEOt has gastroprotective property, which may be related to antioxidant capacity of the phenolic compounds present in the extract. These results corroborate with the indication of popular use of this species in the treatment of gastric ulcers.

Keywords: Antioxidant, Avicennia schaueriana, Gastroprotective.

*Correspondence to Author:

Borba A.D.L

Student of the Pharmacy Course UFPE

How to cite this article:

Borba A.D.L; Barbosa J.A.P; Santana M.A.N; Coutinho L.L; Farias L.O; Silva T.G. Evaluation of antioxidant and gastroprotective activities of ethyl acetate extract of Avicennia schaueriana.International Journal of Biomedical Engineering Research, 2018, 1:5

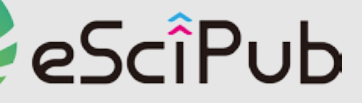

eSciPub LLC, Houston, TX USA. Website: http://escipub.com/ 